\title{
Evaluation of naphthoquinones identified the acetylated isolapachol as a potent and selective antiplasmodium agent
}

Diogo R. M. Moreira, Matheus S. de Sá, Taís S. Macedo, Maria N. Menezes, José Rui M. Reys, Antônio E. G. Santana, Thaissa L. Silva, Gabriela L. A. Maia, José M. Barbosa-Filho, Celso A. Camara, Tania M. S. da Silva, Katia N. da Silva, Elisalva T. Guimaraes, Ricardo R. dos Santos, Marília O. F. Goulart \& Milena B. P. Soares

To cite this article: Diogo R. M. Moreira, Matheus S. de Sá, Taís S. Macedo, Maria N. Menezes, José Rui M. Reys, Antônio E. G. Santana, Thaissa L. Silva, Gabriela L. A. Maia, José M. BarbosaFilho, Celso A. Camara, Tania M. S. da Silva, Katia N. da Silva, Elisalva T. Guimaraes, Ricardo R. dos Santos, Marília O. F. Goulart \& Milena B. P. Soares (2015) Evaluation of naphthoquinones identified the acetylated isolapachol as a potent and selective antiplasmodium agent, Journal of Enzyme Inhibition and Medicinal Chemistry, 30:4, 615-621, DOI: 10.3109/14756366.2014.958083

To link to this article: http://dx.doi.org/10.3109/14756366.2014.958083

Published online: 28 Nov 2014.

LII Article views: 106
Submit your article to this journal $\widetilde{ }$ 


\title{
Evaluation of naphthoquinones identified the acetylated isolapachol as a potent and selective antiplasmodium agent
}

\author{
Diogo R. M. Moreira ${ }^{1,2}$, Matheus S. de Sá1, Taís S. Macedo ${ }^{1}$, Maria N. Menezes ${ }^{1}$, José Rui M. Reys ${ }^{3}$, \\ Antônio E. G. Santana ${ }^{3}$, Thaissa L. Silva ${ }^{3}$, Gabriela L. A. Maia ${ }^{4}$, José M. Barbosa-Filho ${ }^{4}$, Celso A. Camara ${ }^{5}$, \\ Tania M. S. da Silva ${ }^{5}$, Katia N. da Silva ${ }^{2}$, Elisalva T. Guimaraes ${ }^{1}$, Ricardo R. dos Santos ${ }^{2}$, Marília O. F. Goulart ${ }^{3}$, and \\ Milena B. P. Soares ${ }^{1}$
}

${ }^{1}$ Fundação Oswaldo Cruz, Centro de Pesquisas Gonçalo Moniz, Salvador, BA, Brazil, ${ }^{2}$ Centro de Biotecnologia e Terapia Celular, Hospital São Rafael, Salvador, BA, Brazil, ${ }^{3}$ Instituto de Química e Biotecnologia, Universidade Federal de Alagoas, Maceió, AL, Brazil, ${ }^{4}$ Laboratório de Tecnologia Farmacêutica, Universidade Federal da Paraíba, João Pessoa, PB, Brazil, and ${ }^{5}$ Departamento de Química, Universidade Federal Rural de Pernambuco, Recife, PE, Brazil

\begin{abstract}
This study reports on the design, synthesis and antiparasitic activity of three new semi-synthetic naphthoquinones structurally related to the naturally-occurring lapachol and lapachone. Of the compounds tested, 3-(3-methylbut-1-en-1-yl)-1,4-dioxo-1,4-dihydronaphthalen-2-yl acetate (1) was the most active against Plasmodium falciparum among both natural and semi-synthetic naphthoquinones, showing potent and selective activity. Compound $\mathbf{1}$ was able to reduce the in vitro parasite burden, in vitro parasite cell cycle, as well as the blood parasitemia in Plasmodium berghei-infected mice. More importantly, infection reduction under compound 1-treatment was achieved without exhibiting mouse genotoxicity. Regarding the molecular mechanism of action, this compound inhibited the hemozoin crystal formation in $P$. falciparum treated cells, and this was further confirmed by observing that it inhibits the $\beta$-hematin polymerization process similarly to chloroquine. Interestingly, this compound did not affect either mitochondria structure or cause DNA fragmentation in parasite treated cells. In conclusion, we identified a semi-synthetic antimalarial naphthoquinone closely related to isolapachol, which had stronger antimalarial activity than lapachol.
\end{abstract}

Keywords

Antiparasitic agents, hemozoin, malaria, mitochondria, naphthoquinones, Plasmodium falciparum

\section{History}

Received 5 July 2014

Revised 16 August 2014

Accepted 17 August 2014

Published online 27 November 2014

\section{Introduction}

Malaria represents a major threat to the public health worldwide, with over 250 million clinical cases and two million deaths annually ${ }^{1,2}$. Most Plasmodium falciparum isolates in endemic areas have developed multi-resistance to the aminoquinolines (chloroquine, amodiaquine and mefloquine) ${ }^{3}$. Because of this, artemisinin derivatives are recommended in combination with aminoquinolines and other drugs to treat the infection caused by multidrug resistant strains ${ }^{4}$. Resistance to artemisinin has been reported $^{5}$, making the development of new antimalarial drugs necessary.

Naphthoquinones are a useful chemical class for antiparasitic drug development ${ }^{6-10}$. This is well exemplified by buparvaquone, parvaquone and atovaquone, the latter being used in a fixed-dose combination with proguanil for treating drug-resistant $P$. falciparum malaria ${ }^{11-13}$. Based on this, other naphthoquinones

Address for correspondence: Milena B. P. Soares, Fundação Oswaldo Cruz, Centro de Pesquisas Gonçalo Moniz, Rua Waldemar Falcão, n. 121, Candeal - Salvador, BA 40296-710, Brazil. Tel: +55-71-3176-2292. Fax: +55-71-3176-2272. E-mail: milena@bahia.fiocruz.br have been investigated as antimalarials in potential. Specifically, the naturally-occurring naphthoquinones lapachol and $\alpha$ - and $\beta$-lapachones have a broad spectrum antimalarial activity against the erythrocytic and liver stages in both chloroquine-sensitive and chloroquine-resistant strains ${ }^{6,14}$. Like atovaquone, these naphthoquinones affect Plasmodium growth, in part, by impairing mitochondrial function, which affects the electron transport flux and subsequently prevents hemozoin formation ${ }^{15,16}$. In view of this, naphthoquinones are considered promising antimalarial agents. In recent years, chemical modifications in the naphthoquinone backbone, as well as in the side chain, have identified derivatives with enhanced antimalarial activity ${ }^{17-22}$.

Based on the structure-activity relationship observed for lapachol and $\alpha$ - and $\beta$-lapachones, here we prepared for the first time three derivatives denoted as compounds $\mathbf{1 - 3}$ and evaluated the antimalarial activity. Compound $\mathbf{1}$ is the acetylated form of isolapachol, while compounds $\mathbf{2}$ and $\mathbf{3}$ are semi-synthetic naphthopyrandiones containing an iodine substituent. By evaluating the antiparasitic activity of these derivatives and comparing the potency to their naturally-occurring analogs, we observed an enhancement of activity for compound $\mathbf{1}$ in comparison to lapachol. In addition, compound $\mathbf{1}$ was able to inhibit the Plasmodium life cycle in erythrocytes, inhibited hematin crystal 
formation, but had little effect on Plasmodium mitochondrial activity. Finally, compound $\mathbf{1}$ was able to reduce blood parasitemia in $P$. berghei-infected mice, and importantly, this was achieved without exhibiting mouse toxicity or genotoxicity.

\section{Materials and methods}

\section{Compound preparation}

2-Hydroxy-3-(3-methylbut-2-en-1-yl)naphthalene-1,4-dione (lapachol) was extracted from the bark of Tabebuia aurea (Manso) S. Moore by using a previously described method ${ }^{23}$. Yellow crystals of compound 1 were obtained in a 1-2 \% yield from the dry bark. M.p. $137-139^{\circ} \mathrm{C}$ (literature $140^{\circ} \mathrm{C}$ ). 2-Hydroxy-3-(3-methylbut-1-en-1-yl)naphthalene-1,4-dione (isolapachol) was prepared from lapachol according to the methodology described in reference 25 . Yellow crystals, m.p. $76-77^{\circ} \mathrm{C}$. 2,2-Dimethyl-3,4-dihydro- $2 H$-benzo[ $g$ ]chromene-5,10-dione $(\alpha$-lapachone) was prepared from lapachol following a modified Hooker procedure ${ }^{24}$. Red crystals, m.p. $152-154^{\circ} \mathrm{C}$. Yield $=76 \%$. 2,2-Dimethyl-3,4-dihydro-2H-benzo[ $h]$ chromene-5,6-dione ( $\beta$-lapachone) was prepared from lapachol following the methodology described above. Yellow crystals, m.p. $113-115^{\circ} \mathrm{C}$. Yield $=14 \%$ (Figure 1).

3-(3-Methylbut-1-en-1-yl)-1,4-dioxo-1,4-dihydronaphthalen-2$y$ l acetate $(1)$ in a $100 \mathrm{~mL}$ round bottom flask, isolapachol $(2.0 \mathrm{~g}$, $8.2 \mathrm{mmol}$ ) was dissolved in $13 \mathrm{~mL}$ of acetic anhydride and stirred at room temperature. Anhydrous NaOAc (2.0 g, $3.9 \mathrm{mmol})$ was added to the mixture and the reaction mixture was then maintained under stirring for $30 \mathrm{~min}$, under heating at $100{ }^{\circ} \mathrm{C}$. After this time, the mixture was cooled to room temperature, ice was added, which was followed by compound precipitation.<smiles>CC(C)=CCC1=C(O)C(=O)c2ccccc2C1=O</smiles>

lapachol<smiles>CC1(C)CCC2=C(O1)C(=O)c1ccccc1C2=O</smiles>

$\alpha$-lapachone<smiles>CCCCC1(C)CCC2=C(O1)c1ccccc1C(=O)C2=O</smiles><smiles>CC(=O)OC1=C(/C=C/C(C)C)C(=O)c2ccccc2C1=O</smiles><smiles>CC1(C)OC2=C(CC1I)C(=O)c1ccccc1C2=O</smiles>

(2)<smiles>CC1(C)OC2=C(CC1I)C(=O)C(=O)c1ccccc12</smiles>

(3)
Figure 1. Structures of naphthoquinones investigated here as anti-P. falciparum compounds.
The solid was recrystallized in ethanol. Yellow crystals, m.p. 75.6-76.3 ${ }^{\circ} \mathrm{C}$, Yield $=54 \%$. ${ }^{1} \mathrm{H}$ NMR $\left(200 \mathrm{MHz}, \mathrm{CDCl}_{3}, \delta\right): 1.09$ $\left(3 \mathrm{H}, \mathrm{s}, \mathrm{CH}_{3}\right), 1.13\left(3 \mathrm{H}, \mathrm{s}, \mathrm{CH}_{3}\right), 2.42\left(3 \mathrm{H}, \mathrm{s},-\mathrm{OCOCH}_{3}\right)$, 2.47-2.60 (1H, m, H-3'), $6.36\left(1 \mathrm{H}, \mathrm{d}, J 16.2 \mathrm{~Hz}, \mathrm{H}-1^{\prime}\right), 6.95(1 \mathrm{H}$, $\left.\mathrm{dd}, J=7.2,16.2 \mathrm{~Hz}, \mathrm{H}-2^{\prime}\right), 7.68-7.75(2 \mathrm{H}, \mathrm{m}, \mathrm{H}-6$ and $\mathrm{H}-7)$, 8.05-8.13 (2H, m, H-5 and H-8). HRESIMS calculated for $\mathrm{C}_{17} \mathrm{H}_{16} \mathrm{O}_{4}: 284.1048$; found: $285.1079[\mathrm{M}+1]^{+}$.

3-Iodo-2,2-dimethyl-3,4-dihydro-2H-benzo[g]chromene-5,10dione (2) was prepared from $\alpha$-lapachone following the methodology previously described ${ }^{25}$. Yellow crystals, m.p. $108-112^{\circ} \mathrm{C}$. Yield $=36 \%$. HRESIMS calculated for $\mathrm{C}_{15} \mathrm{H}_{13} \mathrm{O}_{3} \mathrm{I}$ : 367.9909; found: $368.9965[\mathrm{M}+1]^{+}$.

3-Iodo-2,2-dimethyl-3,4-dihydro-2H-benzo[h]chromene-5,6dione (3) was prepared from $\beta$-lapachone following the previously described method ${ }^{25}$. Red crystals, m.p. $137-138^{\circ} \mathrm{C}$. Yield $=54 \%$. HRESIMS calculated for $\mathrm{C}_{15} \mathrm{H}_{13} \mathrm{O}_{3} \mathrm{I}$ : 367.9909; found: 369.0011 $[\mathrm{M}+1]^{+}$.

\section{Mice and cells}

BALB/c and Swiss Webster mice were supplied by the animal breeding facility at Centro de Pesquisas Gonçalo Moniz (Salvador, Brazil) and maintained in sterilized cages under a controlled environment, receiving a balanced diet for rodents and water ad libitum. Spleens of BALB/c mice were removed in accordance with the guidelines of the Commission for Experiments in Laboratory Animals. P. falciparum (W2 strain) was maintained in a continuous culture of human erythrocytes (blood group $\mathrm{O}^{+}$) using Roswell Park Memorial Institute-1640 (RPMI-1640) medium (Sigma-Aldrich, St. Louis, MO) supplemented with $10 \%$ human plasma. BALB/c mouse splenocytes were cultured in Dulbecco's modified Eagle's medium (DMEM; Sigma-Aldrich) supplemented with $10 \%$ fetal calf serum (Cultilab, Campinas, Brazil) and $50 \mu \mathrm{g} / \mathrm{mL}$ of gentamycin (Novafarma, Anapolis, Brazil). Mefloquine and chloroquine were kindly supplied by FarManguinhos (Rio de Janeiro, Brazil), and cyclophosphamide was purchased from SigmaAldrich. Drugs were dissolved in DMSO (Sigma-Aldrich) and diluted in media to a final concentration of $0.5 \%$ dimethylsulfoxide (DMSO). All procedures described here had prior approval from the local animal ethics committee.

\section{Cytotoxicity in splenocytes}

BALB/c mouse splenocytes $\left(6 \times 10^{5}\right.$ cells/well $)$ were distributed in a 96-well plate. Compounds previously dissolved in DMSO were diluted in DMEM and added to the cell cultures. Five compound concentrations were used, each one in triplicate. Cells were incubated with drugs for $24 \mathrm{~h}$, then $1.0 \mu \mathrm{Ci} /$ well $\left[{ }^{3} \mathrm{H}\right]-$ thymidine (PerkinElmer, Boston, MA) was added to the cultures and incubated for $24 \mathrm{~h}$ at $37^{\circ} \mathrm{C}$ and $5 \% \mathrm{CO}_{2}$. After this time, cells were harvested using the cell harvester (Brandel MPXRI 96TI, Gaithersburg, MD) and the $\left[{ }^{3} \mathrm{H}\right]$-thymidine incorporation was determined by using a $\beta$-radiation counter (Hidex Multilabel Reader, Turku, Finland). Cell viability was determined in comparison to untreated cultures. The cytotoxic concentration to $50 \%\left(\mathrm{CC}_{50}\right)$ was calculated, using non-linear regression. Two independent experiments in triplicate were performed.

In vitro anti-P. falciparum activity

Parasites grown at $1-1.5 \%$ parasitemia and $2.5 \%$ hematocrit were distributed into 96-wells plate. Compounds were dissolved in DMSO followed by serial dilution in RPMI-1640 medium without hypoxanthine. Five compound concentrations were used, each one in triplicate. After $24 \mathrm{~h}$ incubation time, $0.5 \mu \mathrm{Ci} /$ well $\left[{ }^{3} \mathrm{H}\right]-$ hypoxanthine monochloride (PerkinElmer, Boston, MA) was 
added, incubated for $24 \mathrm{~h}$ and then cells were harvested using the cell harvester (Brandel MPXRI 96TI) and the $\left[{ }^{3} \mathrm{H}\right]$-hypoxanthine incorporation was determined by using a $\beta$-radiation counter (Hidex Multilabel Reader). Inhibition of parasite growth was determined in comparison to untreated cultures. The inhibitory concentration to $50 \%\left(\mathrm{IC}_{50}\right)$ was calculated using non-linear regression. Two independent experiments in triplicate were performed.

\section{Activity on the P. falciparum cell cycle}

Parasites grown at 2\% parasitemia and 2.5\% hematocrit were synchronized to ring stage by using sorbitol (5\%). Cells were then treated with compound 1 and incubated until $48 \mathrm{~h}$ at $37^{\circ} \mathrm{C}$. Thin blood films were prepared and stained with fast panoptic (Laborclin, Pinhais, Brazil) and examined by optical microscopy. Parasitemia was determined by counting at least 1000 erythrocytes per multiple sections of each slide and the results were pooled and data analyzed for statistical significance. Two independent experiments in triplicate were performed.

\section{Transmission electron microscopy (TEM)}

Parasite cultures were treated with $2.3 \mu \mathrm{M}$ of compound 1 and incubated for $24 \mathrm{~h}$ at $37^{\circ} \mathrm{C}$. Untreated parasites were used as controls. After incubation, the parasites were fixed with $2.5 \%$ glutaraldehyde in $0.1 \mathrm{M}$ cacodylate buffer $(\mathrm{pH} 7.2)$ and post-fixed with the same buffer containing $1 \% \quad \mathrm{OsO}_{4}, 0.8 \%$ potassium ferricyanide, and $5.0 \mathrm{mM}$ calcium chloride for $40 \mathrm{~min}$ at room temperature, in the absence of light. Then, parasites were washed in the same buffer and dehydrated on increasing concentrations of acetone (30-100\%) for $10 \mathrm{~min}$ in each concentration. Polymerization was achieved with polybed epoxy resin (Polysciences, Warrington, FL). Ultrathin slices were contrasted with uranyl acetate and lead citrate and observed in an EM109 electron microscope (Zeiss, Oberkochen, Germany).

\section{Hemolysis assay}

Fresh human erythrocytes (type $\mathrm{O}^{+}$) were washed three times in PBS and resuspended in the same buffer to a $1 \%$ hematocrit solution, from which $100 \mu \mathrm{L}$ were distributed per well in 96-well plates. Compound 1, previously dissolved in phosphate buffered saline, was added at $200 \mu \mathrm{M}$, in triplicate, and plates were incubated for $1 \mathrm{~h}$ at $37^{\circ} \mathrm{C}$. Saponin (Sigma-Aldrich) was used as a hemolytic drug at $1 \% \mathrm{v} / \mathrm{v}$. After incubation, plates were centrifuged ( $1500 \mathrm{rpm}$ for $10 \mathrm{~min}$ ) and $100 \mu \mathrm{L}$ of each supernatant was transferred to a microtiter plate. Released hemoglobin was quantified by measuring the absorbance at $540 \mathrm{~nm}$ in a spectrophotometer. The percentage of hemolysis was calculated in comparison to untreated cells. Two independent experiments in triplicate were performed.

\section{Inhibition of $\beta$-hematin formation}

Fifty microliters of a freshly prepared solution of hemin $(0.5 \mathrm{mg} / \mathrm{mL})$ dissolved in $0.2 \mathrm{M} \mathrm{NaOH}$ were mixed to a $75 \mu \mathrm{L}$ of $3 \mathrm{M}$ sodium acetate, $25 \mu \mathrm{L}$ of $17.4 \mathrm{M}$ acetic acid and $50 \mu \mathrm{L}$ of the compounds. Each compound was tested in five concentrations, each one in triplicate. After $24 \mathrm{~h}$ of incubation at $37^{\circ} \mathrm{C}$, the resulting solution was spun down for $15 \mathrm{~min}$ at $3500 \mathrm{rpm}$ and the pellet was washed with $200 \mu \mathrm{L}$ of DMSO. This step was repeated once and, after a final wash with water, the pellet was dissolved in $0.1 \mathrm{M} \mathrm{NaOH}(150 \mu \mathrm{L})$. The absorption was read at $405 \mathrm{~nm}$ using a spectrophotometer (SpectraMAX model 190, Molecular Devices, Sunnyvale, CA). Results are expressed as percentage of inhibition of hematin formation in comparison to the negative control (without the compounds).
Experiments were carried out at least twice, using compound concentrations in triplicate.

\section{Determination of $\mathrm{P}$. falciparum DNA integrity by TUNEL assay}

DNA fragmentation was tested through a TUNEL assay kit (APODIRECT $^{\mathrm{TM}}$, BD Pharmingen, San Jose, CA). P. falciparum ring stages were cultured with the compound $1(2.3,11.7$ and $23.5 \mu \mathrm{M})$ for $24 \mathrm{~h}$ at $37^{\circ} \mathrm{C}$. Free parasites were obtained from their host erythrocytes by treatment with $0.1 \%$ saponin (w/v) in PBS. Untreated parasite (negative control) was included in the experiment. The parasites were washed with PBS (1500 rpm for $5 \mathrm{~min}$ ), fixed for $1 \mathrm{~h}$ at $4{ }^{\circ} \mathrm{C}$ with $1 \%$ paraformaldehyde in PBS and permeabilized with $70 \%$ ice-cold ethanol according to the manufacturer's recommendations. Reaction solution was incubated for $1 \mathrm{~h}$ at $37^{\circ} \mathrm{C}$. The total DNA was stained by incubation with a solution containing propidium iodide (PI)/ Ribonuclease (RNase). Fluorescein isothiocyanate-deoxyuridine triphosphate (FITC-dUTP) was analyzed at $520 \mathrm{~nm}$, while PI was at $623 \mathrm{~nm}$. Deoxynuclease (DNase, Life Technologies, Foster City, CA) was used as positive control at $37^{\circ} \mathrm{C}$ for $30 \mathrm{~min}$ at 2 units $/ \mu \mathrm{L}$. Cell acquisition was performed using a BD Calibur flow cytometer by acquiring 10000 events and data were analyzed by BD CellQuest. Two independent experiments in triplicate were performed.

\section{Determination of parasite mitochondrial membrane potential $(\Delta \Psi m)$}

Changes in parasite mitochondrial membrane potential were determined with 3,3'-dihexyloxacarbocyanine iodide probe (DiOC, Life Technologies). Parasitized red blood cells enriched for trophozoite stage were resuspended in RPMI medium and incubated with DiOC (2 $\mathrm{nM}$ final concentration) for $20 \mathrm{~min}$ at $37^{\circ} \mathrm{C}$. The compound $(2.3,11.7$ and $23.5 \mu \mathrm{M})$ was then added and incubated for $20 \mathrm{~min}$. Carbonyl cyanide $m$-chlorophenylhydrazone (CCCP, Sigma-Aldrich) was used as a positive control at $100 \mu \mathrm{M}$. Changes in the fluorescence by DiOC incorporation into mitochondria membranes of parasitized red blood cells were evaluated using a BD Calibur flow cytometer by acquiring 10000 events, and data were analyzed by BD CellQuest software.

\section{Antiparasitic activity in $\mathrm{P}$. berghei-infected mice}

Swiss Webster mice were infected by intraperitoneal route with $10^{6}$ red blood cells infected with the $P$. berghei NK65 strain. Animals were randomly sorted into $n=5$ /group. Two hours postinfection, treatment was given once a day during four consecutive days. Drugs were dissolved in saline containing 20\% DMSO and each mouse received $200 \mu \mathrm{L}$ by intraperitoneal or oral (gavage) route. Untreated infected group received only saline containing $20 \%$ DMSO. The antimalarial activity was evaluated by counting parasitemia in blood smears in the 4-8 d post-infection. Cells were fixed in methanol, stained with fast panoptic (Laborclin, Pinhais, Brazil) and examined by optical microscopy. Mortality was followed up until $30 \mathrm{~d}$ post-infection.

\section{Micronucleus test}

Uninfected Swiss Webster mice (male, 20-25 g, $n=5$ ) were treated by intraperitoneal injection with $100 \mathrm{mg} / \mathrm{kg}$ body weight of compound 1. Eighteen to $24 \mathrm{~h}$ after treatment, femurs from each animal were dissected and bone marrow was washed with fetal bovine serum (Gibco, Foster City, CA). Bone marrow smears were prepared on glass slides after centrifugation at $2000 \mathrm{rpm}$ ( 5 min). Slides were air-dried and stained using Wright-Giemsa and evaluated using an optical microscope. The polychromatic erythrocyte (PCE) and mononucleated polychromatic erythrocyte (NPCE) number and ratio were established for each animal by 
scoring a total of 8000 erythrocytes (PCE + NPCE). Bone marrow preparations were evaluated for the presence of micronuclei by counting 1000 PCE for each animal. One experiment was performed.

\section{Statistical analysis}

Nonlinear regression was calculated in GraphPad Prism version 4.0 (Graph Pad software, San Diego, CA). Two way ANOVA test was used and differences were considered significant for $p<0.05$.

\section{Results}

\section{Antiparasitic activity and cytotoxicity}

The antiparasitic activity was evaluated in intraerythrocytic forms of $P$. falciparum W2 strain. Cytotoxicity was evaluated in mouse splenocytes. Mefloquine was used as an antimalarial reference drug. Activity was described in term of $\mathrm{IC}_{50}$ and $\mathrm{CC}_{50}$ values (Table 1). Lapachol exhibited low antiparasitic activity, while isolapachol did not show activity (data not shown). Compound $\mathbf{1}$ was substantially more active than lapachol, displaying an $\mathrm{IC}_{50}$ of $2.3 \pm 0.1 \mu \mathrm{M}$. $\alpha$ - and $\beta$-lapachones exhibited $\mathrm{IC}_{50}$ of $15.8 \pm 3.5$ and $20.5 \pm 1.0 \mu \mathrm{M}$, respectively, being more potent than lapachol. The synthetic lapachone derivatives $\mathbf{2}$ and $\mathbf{3}$ displayed equal antiparasitic activity as observed for naturally-occurring lapachones. Following this, cytotoxicity to mouse splenocytes was analyzed. In comparison to mefloquine, which exhibited $\mathrm{CC}_{50}$ of $5.2 \pm 0.4 \mu \mathrm{M}$, lapachol and compound 2 were less cytotoxic. Other compounds exhibited similar or higher cytotoxicity than mefloquine. Regarding the selectivity index, compound $\mathbf{1}$ presented higher selectivity than lapachol, although it was less selective than mefloquine.

\section{P. falciparum cell cycle}

Compound 1 was the most potent antiparasitic naphthoquinone, and thus was selected to evaluate its effect in the parasite intracellular development in host cells. In this assay, W2 strain of $P$. falciparum was synchronized to ring-stage and incubated until $48 \mathrm{~h}$ in the presence of compound 1 at $2.3 \mu \mathrm{M}\left(\mathrm{IC}_{50}\right)$ and $4.7 \mu \mathrm{M}$ $\left(\mathrm{IC}_{100}\right)$. The distribution of rings, schizonts and trophozoites in erythrocytes was counted by optical microscope. In untreated cells, ring-stage parasites maturate to trophozoites after $24 \mathrm{~h}$ of incubation and at $48 \mathrm{~h}$ of incubation, a number of schizonts are observed. As can be seen in Figure 2, compound 1 at $2.3 \mu \mathrm{M}$ substantially reduced the ring-stage maturation into schizonts. In addition, compound $\mathbf{1}$ treatment prevented the formation of schizonts in the cell culture. Furthermore, we evaluated the

Table 1 . In vitro antiparasitic activity and cytotoxicity.

\begin{tabular}{lccc}
\hline Compounds & $\begin{array}{c}\text { P. falciparum W2 strain } \\
\mathrm{IC}_{50} \pm \mathrm{SD}(\mu \mathrm{M})^{\mathrm{a}}\end{array}$ & $\begin{array}{c}\text { Splenocytes } \\
\mathrm{CC}_{50} \pm \mathrm{SD}(\mu \mathrm{M})^{\mathrm{b}}\end{array}$ & SI $^{\mathrm{c}}$ \\
\hline lapachol & $80.4 \pm 20$ & $26.2 \pm 3.5$ & 0.3 \\
Compound $\mathbf{1}$ & $2.3 \pm 0.1$ & $9.07 \pm 0.9$ & 3 \\
$\alpha$-lapachone & $15.8 \pm 3.5$ & $13.9 \pm 0.8$ & 0.8 \\
Compound 2 & $19.4 \pm 1.7$ & $21.4 \pm 1.0$ & 1.1 \\
$\beta$-lapachone & $20.5 \pm 1.0$ & $3.0 \pm 0.5$ & 0.1 \\
Compound 3 & $15.8 \pm 2.0$ & $13.7 \pm 0.5$ & 0.8 \\
mefloquine & $0.04 \pm 0.01$ & $5.2 \pm 0.4$ & 131 \\
\hline
\end{tabular}

\footnotetext{
${ }^{a}$ Antiparasitic activity was determined in erythrocytic $P$. falciparum after $48 \mathrm{~h}$ incubation with the compounds.

${ }^{\mathrm{b}}$ Cytotoxicity was determined in splenocytes after $24 \mathrm{~h}$ incubation with the compounds.

${ }^{\mathrm{c}} \mathrm{SI}$ : selectivity index, calculated from the $\mathrm{CC}_{50} / \mathrm{IC}_{50}$. SD: standard deviation of two experiments.
}

hemolytic effect of compound $\mathbf{1}$ in uninfected erythrocytes. As shown in Table 2, it did not induce hemolysis in concentrations up to $200 \mu \mathrm{M}$.

\section{Investigating the mechanism of action}

We used TEM to examine the ultrastructural morphology of intraerythrocytic parasites treated with compound 1. In untreated parasite, the presence of needle-like structures characteristic of hemozoin formation is observed (Figure 3). In contrast to the untreated control, compound $\mathbf{1}$ treatment inhibited the formation of hemozoin crystals inside of digestive parasitic vacuoles. Moreover, it was observed that compound $\mathbf{1}$ treatment alters morphology in parasite cells, characteristic of parasiticidal agents. To corroborate to the hemozoin inhibition finding, the ability of compound 1 to inhibit the $\beta$-hematin formation was determined. Chloroquine, the reference drug, inhibited $\beta$-hematin formation with an $\mathrm{IC}_{50}$ of $0.86 \pm 0.30 \mathrm{mM}$. Compound 1 exhibited similar property of $\beta$-hematin inhibition, while lapachol exhibited low activity (Table 2).

In the second set of experiments, we treated W2 strain $P$. falciparum with different concentrations of compound $\mathbf{1}$, incubated for $24 \mathrm{~h}$ and evaluated mitochondria impairment as well as DNA fragmentation. Cells were stained with DIOC or by using TUNEL kit assay and examined by flow cytometry. When compared to untreated cells, CCCP-treatment caused cell depolarization, leading to cells positively stained for DIOC. In contrast,

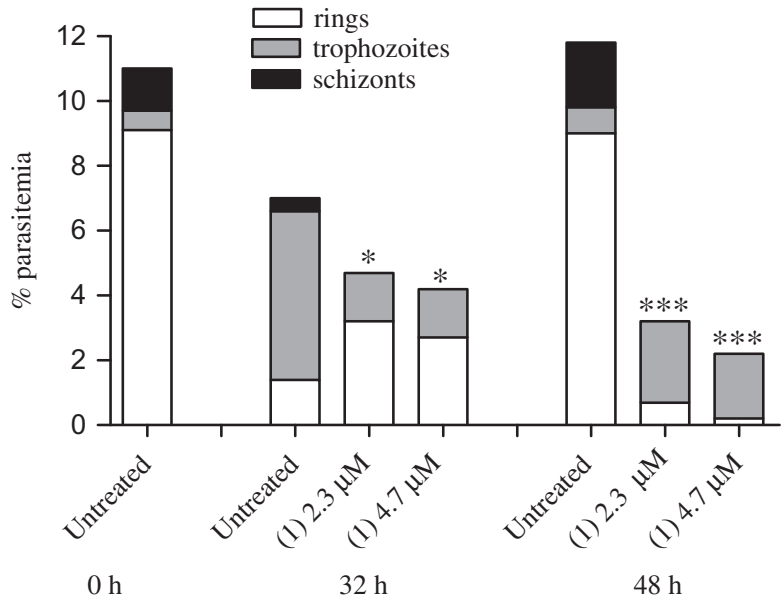

Figure 2. Antiparasitic activity of compound $\mathbf{1}$ in the cell-cycle development of blood-stage P. falciparum. Erythrocytes were infected with W2 strain P. falciparum (synchronized to ring stage) and incubated with compound 1 at 2.3 and $4.7 \mu \mathrm{M}$ during one cycle. Parasites were analyzed by optical microscopy in different times. Significance in reference to $\%$ of parasitemia: ${ }^{*} p<0.05 ; * * * p<0.001$.

Table 2. Effects on the hematin formation and hemolysis.

\begin{tabular}{lccccc}
\hline & \multicolumn{2}{c}{ Hematin formation ${ }^{\mathrm{a}}$} & & \multicolumn{2}{c}{ Hemolysis $^{\mathrm{b}}$} \\
\cline { 2 - 3 } \cline { 5 - 6 } Compounds & $\begin{array}{c}\text { \% inhibition } \\
\text { at } 2.0 \mathrm{mM}\end{array}$ & $\begin{array}{c}\mathrm{IC}_{50} \pm \mathrm{SD} \\
(\mathrm{mM})^{\mathrm{b}}\end{array}$ & & $\begin{array}{c}\% \text { hemolysis } \\
(200 \mu \mathrm{M})\end{array}$ & $\begin{array}{c}\mathrm{CC}_{50} \pm \mathrm{SD} \\
(\mu \mathrm{M})\end{array}$ \\
\hline lapachol & $38.6 \pm 3.2$ & $>2.0$ & & 5.6 & $>200$ \\
$(\mathbf{1})$ & $89.6 \pm 1.0$ & $0.85 \pm 0.2$ & & 6.3 & $>200$ \\
chloroquine & $61.0 \pm 0.4$ & $0.86 \pm 0.30$ & & - & - \\
mefloquine & - & - & & 36.4 & $>200$ \\
\hline
\end{tabular}

${ }^{a}$ Inhibitory activity was determined after $24 \mathrm{~h}$ incubation with the compounds.

${ }^{\mathrm{b}}$ Hemolysis was determined in uninfected erythrocytes after $1 \mathrm{~h}$ incubation with the compounds. SD: standard deviation of one experiment. 

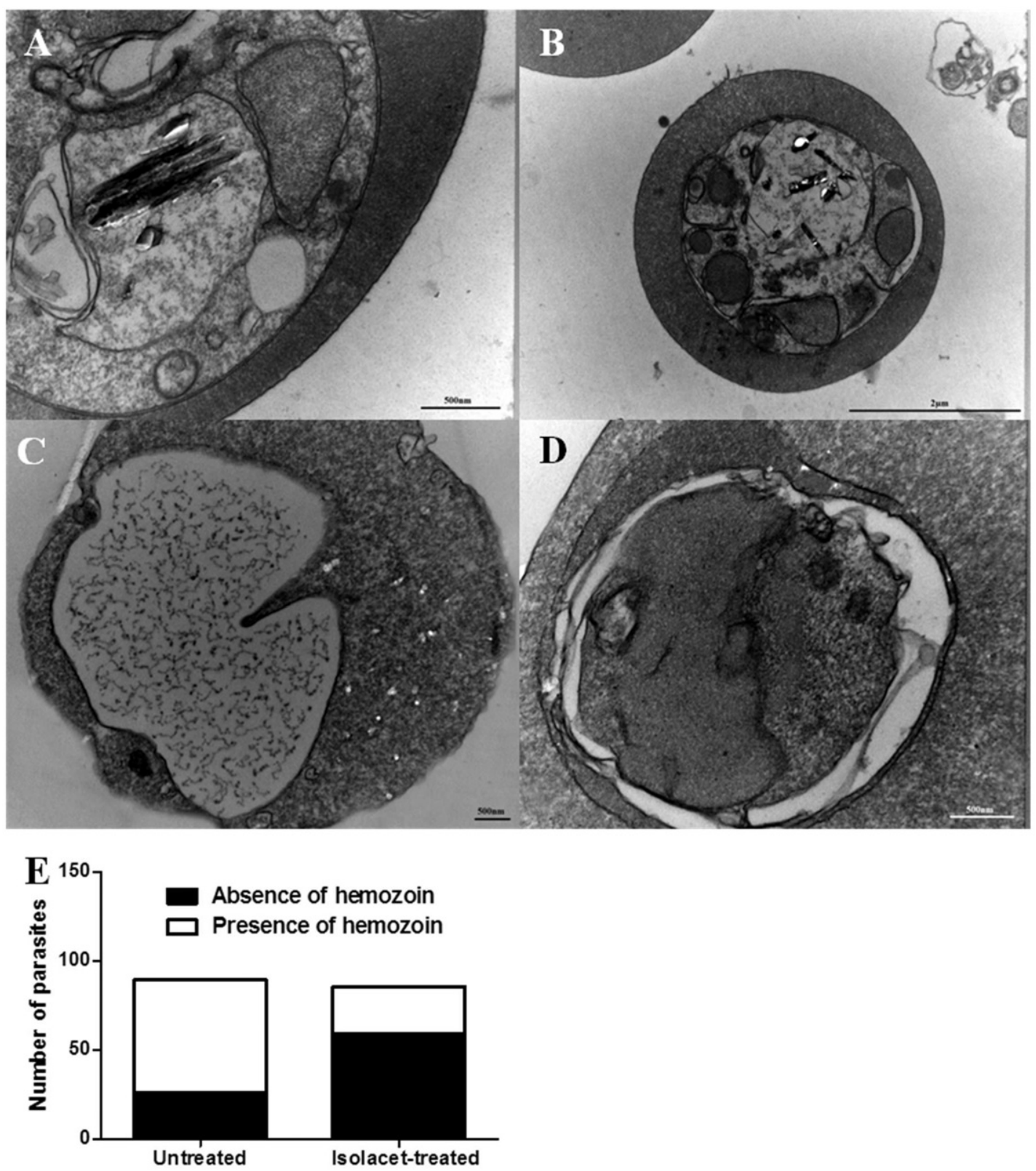

Figure 3. TEM analysis of P. falciparum. Parasites were treated with $2.3 \mu \mathrm{M}$ of compound $\mathbf{1}$ and incubated for $24 \mathrm{~h}$. Panels A and B show untreated parasites, highlighting the presence of hemozoin crystals inside the digestive vacuoles. Panel C and D show treated parasites, where is possible to observe the hemozoin crystal absence. Panel E exhibits the number of parasites containing hemozoin crystals.

parasite cells treated with compound $\mathbf{1}$ were not positively stained for DIOC (data not shown). Therefore, compound 1-based treatment does not cause parasite cell death through mitochondria impairment. By using TUNEL kit assay, an increase in the percentage of stained parasites was observed during DNase treatment at 2 units $/ \mathrm{mL}$ in comparison to untreated parasites (Figure 4). However, parasites treated with compound $\mathbf{1}$ at different concentrations did not present positively stained cells, indicating that this compound does not cause DNA fragmentation in parasitic cells.

\section{P. berghei-infected mice}

Based on the results described above, we evaluated the activity of compound 1 in $P$. berghei-infected Swiss mice. Infected mice receiving saline (untreated group) showed high blood parasitemia after day 4 of parasite inoculation and peaked on day 6 . Chloroquine given orally at $50 \mathrm{mg} / \mathrm{kg}$ once a day for $4 \mathrm{~d}$ starting from day 1 after infection reduced blood parasitemia $(p<0.001)$
(Figure 5, Table 3). Compared to untreated infected mice, intraperitoneal treatment with compound $\mathbf{1}$ at a dose of $10 \mathrm{mg} / \mathrm{kg}$ did not reduce parasitemia, while at doses of 50 and $100 \mathrm{mg} / \mathrm{kg}$, a reduction of parasitemia peak was observed $(p<0.001)$. Compound 1 given orally at $200 \mathrm{mg} / \mathrm{kg}$ reduced $49 \%$ blood parasitemia at day 8 in comparison to untreated infected group, however, this was lower than observed under intraperitoneal treatment at a dose of $100 \mathrm{mg} / \mathrm{kg}$. Mice mortality was monitored up to $30 \mathrm{~d}$ post-infection. In comparison to untreated group, chloroquine treatment decreased mortality (log rank, $p<0.001)$. The groups treated with $100 \mathrm{mg} / \mathrm{kg}$ compound 1 showed no significant difference in mortality rate to untreated group.

\section{Micronucleus test}

We evaluated the genotoxic activity of compound $\mathbf{1}$ in inducing the formation of micronucleus in PCEs. In a control experiment, Swiss Webster mice receiving saline (untreated group) showed a 


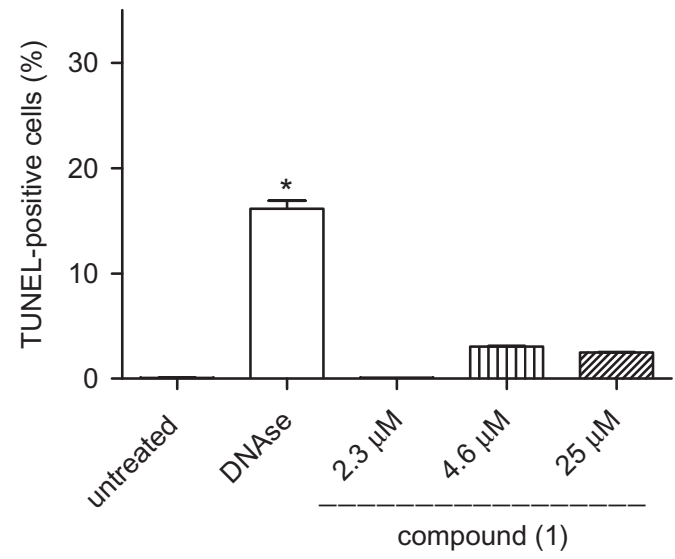

Figure 4. DNA fragmentation in W2 strain P. falciparum incubated with compound 1. Parasites were incubated with $0.05 \%$ DMSO (untreated), DNAse (positive control) or compound $\mathbf{1}$ and then analyzed by flow cytometry by using to the terminal deoxynucleotidyltransferase-mediated dUTP nick end labelling assay (TUNEL). One experiment was performed, in triplicate. $* p<0.001$ in comparison to untreated cells.
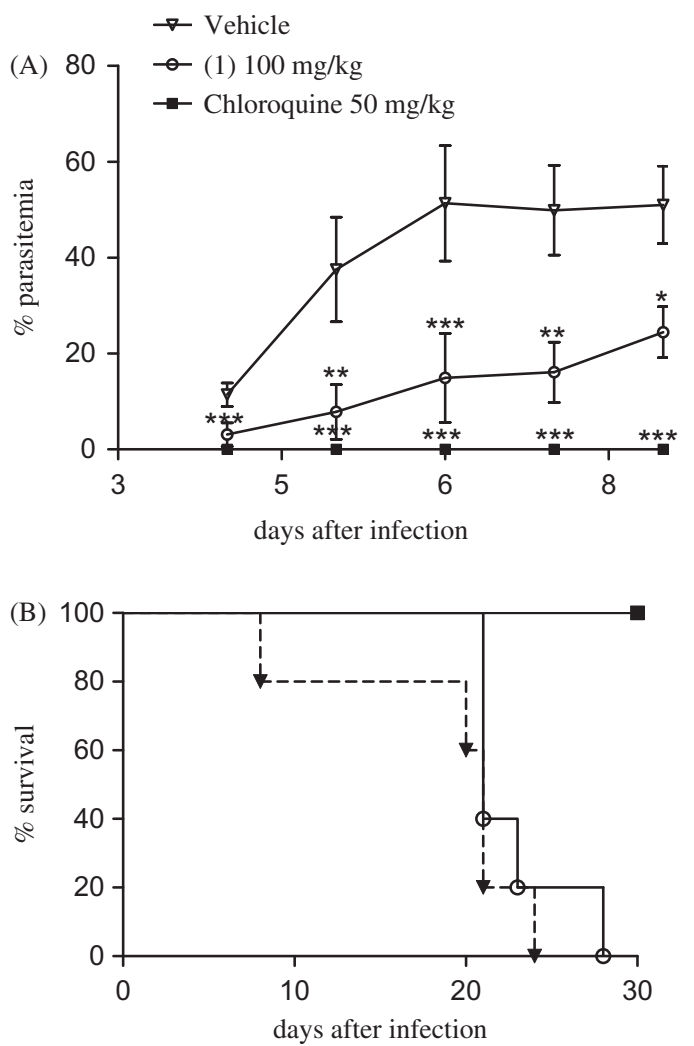

Figure 5. (A) Blood parasitemia and (B) survival in P. berghei-infected mice. Swiss Webster mice ( $n=5 /$ group) were infected with $P$. berghei and then treated daily for four consecutive days. Compound $\mathbf{1}$ was given by intraperitoneal injection, chloroquine by oral gavage. Values represent the means \pm SEM of one experiment $(n=5)$. (A) $* p<0.05 ; * * p<0.01$; $* * * p<0.001$ in comparison to vehicle group. (B) According to the Logrank (Mantel Cox) analysis, there is no statistically significance between vehicle and compound $\mathbf{1}$.

low frequency of micronucleated cells. The reference drug cyclophosphamide given intraperitoneally at $50 \mathrm{mg} / \mathrm{kg}$ increased the frequency of micronucleated cells in comparison to untreated group $(p<0.001)$ (Figure 6). In contrast, intraperitoneal treatment of compound $\mathbf{1}$ at dose $100 \mathrm{mg} / \mathrm{kg}$ did not increase the frequency of micronucleated cells in comparison to the untreated group.
Table 3. Antimalarial activity in $P$. berghei-infected mice.

\begin{tabular}{|c|c|c|c|c|c|c|}
\hline \multirow[b]{2}{*}{ Compounds } & \multirow{2}{*}{$\begin{array}{c}\text { Dose } \\
(\mathrm{mg} / \mathrm{kg}) / \text { route }\end{array}$} & \multicolumn{4}{|c|}{$\%$ parasitemia reduction $^{\mathrm{a}}$} & \multirow{2}{*}{$\begin{array}{c}\text { Survival } \\
\text { (days) }^{\mathrm{b}}\end{array}$} \\
\hline & & Day 5 & 6 & 7 & 8 & \\
\hline Vehicle & Saline / i.p. & - & - & - & - & 19 \\
\hline 1 & 10 / i.p. & 16 & 4.1 & 0 & 15 & 20 \\
\hline 1 & 50 / i.p. & 61 & 59 & 52 & 39 & 24 \\
\hline 1 & $100 /$ i.p. & 79 & 71 & 79 & 65 & 23 \\
\hline 1 & $200 /$ p.o. & 80 & 38 & 63 & 49 & 24 \\
\hline Chloroquine & $50 /$ p.o. & 100 & 100 & 100 & 100 & $>30$ \\
\hline
\end{tabular}

${ }^{\mathrm{a}}$ Determined as $[($ vehicle - treated $) /$ vehicle $] \times 100$.

${ }^{\mathrm{b}}$ Days post-infection. i.p.: intraperitoneal; p.o.: oral administration.

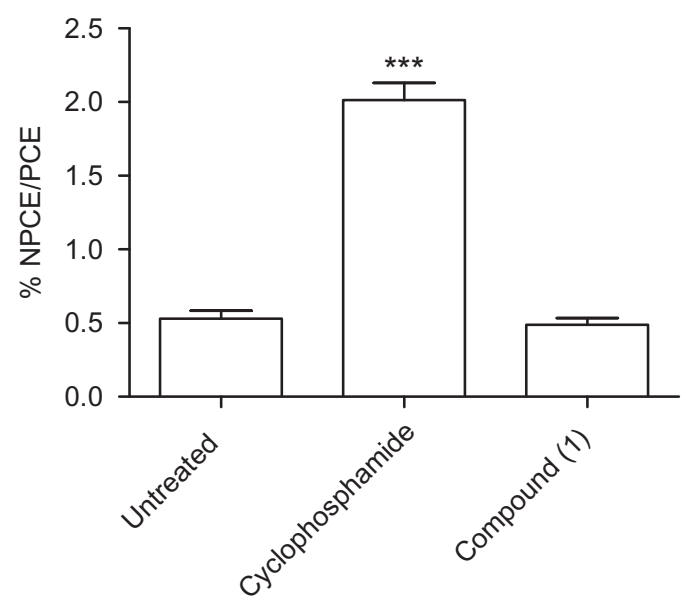

Figure 6. Frequency of micronucleated polychromatic erythrocytes (NPCE) observed in Swiss Webster mouse bone marrow. Swiss mice ( $n=5$ /group) received intraperitoneal injection of saline (untreated), cyclosphophamide $(50 \mathrm{mg} / \mathrm{kg}$ ) and compound $1(100 \mathrm{mg} / \mathrm{kg})$. After 18 to $24 \mathrm{~h}$ of treatment, the percentage of NPCE was determined relatively to 8000 polychromatic erythrocytes (PCE) per group. Values represent the means \pm SEM of one experiment ( $n=5$ /group). ANOVA, $* * * p<0.001$ in comparison to untreated group.

\section{Discussion}

An effective antimalarial treatment continues to be necessary due to acquired resistance of $P$. falciparum to aminoquinoline and artemisin regimes. Screening of isolated natural and semisynthetic compounds is a reliable strategy to identify new anti$P$. falciparum agents. Naphthoquinones are a rich source of antimalarial compounds. Of these, lapachol and lapachones are some of the most investigated in terms of potency and selectivity. In the present study, we determined the anti- $P$. falciparum activity of acetylated isolapachol denoted here as compound $\mathbf{1}$ and of two semi-synthetic naphthopyrandiones (2 and 3) that features an iodine substituent attached in the quinone backbone.

We observed that naphthoquinones (1-3) are anti-Plasmodium agents. Despite the gain in lipophilicity and bulky characteristics usually observed upon halogen atom attachment in drugs ${ }^{26}$, here the incorporation of an iodine substituent into $\alpha$-lapachone (2) and $\beta$-lapachone (3) did not improve the antimalarial activity. In contrast, we observed a substantial enhancement of activity for compound $\mathbf{1}$ in comparison to lapachol. More specifically, it was observed that compound 1 strongly inhibits the erythrocytic form of W2 strain P. falciparum at nontoxic concentrations for mouse macrophages. In addition, compound $\mathbf{1}$ is able to prevent the parasite development into schizonts ${ }^{27}$ and this was achieved without causing hemolysis. 
An examination of parasite morphology revealed that compound 1 inhibits the formation of hemozoin crystals inside the digestive vacuoles. In agreement to this, it was observed that compound 1 but not lapachol, inhibits the $\beta$-hematin formation and this may explain the enhanced antimalarial activity of compound 1 versus lapachol. Hemozoin is vital for parasite maintenance ${ }^{28}$. In fact, we observed that most parasite cells were destroyed under compound $\mathbf{1}$ treatment, suggesting this is a parasiticidal agent. Flow cytometry analysis revealed that compound 1 did not change the mitochondrial transmembrane potential as well as did not cause DNA fragmentation in $P$. falciparum cell culture.

Most importantly, we analyzed compound $\mathbf{1}$ antimalarial activity effects in the in vivo infection. This naphthoquinone was able to reduce the blood parasitemia in a dose-dependent manner. On the one hand, the highest parasitemia reduction was observed under a dose of $100 \mathrm{mg} / \mathrm{kg}$ by intraperitoneal injection. As limitation, this compound did not show substantial antimalarial activity when given orally, probably because it is susceptible to gastric hydrolysis. As advantage, this compound did not exhibit in vivo genotoxicity when evaluated at the same dose it exerts optimal antimalarial activity. Altogether, these findings reinforce that naphthoquinones are active antimalarial agents and at the same time do not cause hemolysis and genotoxicity. Therefore, the screening for new anti- $P$. falciparum naphthoquinones is an attractive line of drug development.

\section{Conclusion}

Three new naphthoquinones were investigated as antimalarial compounds. Of these, the acetylated isolapachol, denoted here as compound 1, exhibited the highest potency and selectivity. This compound inhibits the parasite growth as well as the intracellular development, behaves as a parasiticidal agent and, in parts, exerts antiparasitic activity through inhibiting the formation of hemozoin crystals. Importantly, this compound reduces blood parasitemia in $P$. berghei-infected mice without causing hemolysis or genotoxicity, therefore, suggesting this compound as a starting point for drug design and development of antimalarial agents.

\section{Declaration of interest}

The authors have declared that no competing interests exist.

This work received fundings from Conselho Nacional de Pesquisas Brasileira (CNPq), Fundação de Amparo as Pesquisas do Estado da Bahia (FAPESB), Fundação de Amparo à Pesquisa do Estado de Alagoas (FAPEAL) and Coordenação de Aperfeiçoamento de Pessoal de Nível Superior (CAPES). M.B.P.S., M.O.G.S., A.E.G.S., C.A.C., J.M.B.F. and R.R.S hold a CNPq fellowship. T.S.M. is holding a FAPESB doctoral scholarship, while D.R.M.M. is holding a FAPESB scholarship for visiting scholars.

\section{References}

1. Cotter C, Sturrock HJ, Hsiang MS, et al. The changing epidemiology of malaria elimination: new strategies for new challenges. Lancet 2013;382:900-11.

2. William T, Rahman HA, Jelip J, et al. Increasing incidence of Plasmodium knowlesi malaria following control of P. falciparum and P. vivax Malaria in Sabah, Malaysia. PLoS Negl Trop Dis 2013;7: e2026.

3. Lewis IA, Wacker M, Olszewski KL, et al. Metabolic QTL analysis links chloroquine resistance in Plasmodium falciparum to impaired hemoglobin catabolism. PLoS Genet 2014;10:e1004085.

4. Baird JK. Effectiveness of antimalarial drugs. N Engl J Med 2005; 352:1565-77.

5. Dondorp AM, Nosten F, Yi P, et al. Artemisinin resistance in Plasmodium falciparum malaria. N Engl J Med 2009;361:455-67.
6. Carvalho LH, Rocha EM, Raslan DS, et al. U. In vitro activity of natural and synthetic naphthoquinones against erythrocytic stages of Plasmodium falciparum. Braz J Med Biol Res 1988;21:485-7.

7. Hudson AT, Randall AW, Fry M, et al. Novel anti-malarial hydroxynaphthoquinones with potent broad spectrum anti-protozoal activity. Parasitology 1985;90:45-55.

8. Pinto AV, Ferreira VF, Capella RS, et al. Activity of some naphthoquinones on blood stream forms of Trypanosoma cruzi. Trans Royal Soc Trop Med. Hyg 1987;81:609-10.

9. Santhamma KR and Raj RK. Quinone analogues: a drug of choice for the control of filariasis. Biochem Biophys Res Commun 1993; 190:201-6.

10. Ferguson DJ, Huskinson-Mark J, Araujo FG, Remington JS. An ultrastructural study of the effect of treatment with atovaquone in brains of mice chronically infected with the ME49 strain of Toxoplasma gondii. Int J Exp Pathol 1994;75:111-16.

11. Beerahee M. Clinical pharmacology of atovaquone and proguanil hydrochloride. J Travel Med 1999;6:S13-17.

12. Baggish AL, Hill DR. Antiparasitic agent atovaquone. Antimicrob Agents Chemother 2002;46:1163-73.

13. Nixon GL, Moss DM, Shone AE, et al. Antimalarial pharmacology and therapeutics of atovaquone. J Antimicrob Chemother 2013;68: 977-85.

14. Pérez-Sacau E, Estévez-Braun A, Ravelo AG, et al. Antiplasmodial activity of naphthoquinones related to lapachol and beta-lapachone. Chem Biodiversity 2005;2:264-74.

15. Henry M, Alibert S, Rogier C, et al. Inhibition of efflux of quinolines as new therapeutic strategy in malaria. Curr Top Med Chem 2008;8:563-78.

16. Hughes LM, Lanteri CA, O'Neil MT, et al. Design of anti-parasitic and anti-fungal hydroxy-naphthoquinones that are less susceptible to drug resistance. Mol Biochem Parasitol 2011;177:12-19.

17. De-Andrade-Neto VF, Goulart MO, da Silva-Filho JF, et al. Antimalarial activity of phenazines from lapachol, beta-lapachone and its derivatives against Plasmodium falciparum in vitro and Plasmodium berghei in vivo. Bioorg Med Chem Lett 2004;14: $1145-9$.

18. Lanfranchi DA, Cesar-Rodo E, Bertrand B, et al. Synthesis and biological evaluation of 1,4-naphthoquinones and quinoline-5,8diones as antimalarial and schistosomicidal agents. Org Biomol Chem 2012;10:6375-87.

19. Hussain H, Specht S, Sarite SR, et al. New quinoline-5,8-dione and hydroxynaphthoquinone derivatives inhibit a chloroquine resistant Plasmodium falciparum strain. Eur J Med Chem 2012;54: 936-42.

20. Schuck DC, Ferreira SB, Cruz LN, et al. Biological evaluation of hydroxynaphthoquinones as anti-malarials. Malaria J 2013;12:234. doi:10.1186/1475-2875-12-234

21. Sharma A, Santos IO, Gaur P, et al. Addition of thiols to o-quinone methide: new 2-hydroxy-3-phenylsulfanylmethyl [1,4]naphthoquinones and their activity against the human malaria parasite Plasmodium falciparum (3D7). Eur J Med Chem 2013;59:48-53.

22. De-Rezende LC, Fumagalli F, Bortolin MS, et al. In vivo antimalarial activity of novel 2-hydroxy-3-anilino-1,4-naphthoquinones obtained by epoxide ring-opening reaction. Bioorg Med Chem Lett 2013;23:4583-6.

23. Barbosa-Filho JM, Lima CSA, Amorim ELC, et al. Botanical study, phytochemistry and antimicrobial activity of Tabebuia aurea. Int J Exp Bot 2004;73:221-8.

24. Barbosa TP, Camara CA, Silva TMS, et al. New 1,2,3,4-tetrahydro1-aza-anthraquinones and 2-aminoalkyl compounds from norlapachol with molluscicidal activity. Bioorg Med Chem 2005; 13: 6464-9.

25. Barbosa-Filho JM, Silva TMS, Giulietti AM, et al. Brazilian patent, PI 0403686-7; 2006, 12 pages. CAN 147:448582.

26. Hernandes MZ, Cavalcanti SM, Moreira DR, et al. Halogen atoms in the modern medicinal chemistry: hints for the drug design. Curr Drug Targets 2010;11:303-14.

27. Chalapareddy S, Bhattacharyya MK, Mishra S, Bhattacharyya S. Radicicol confers mid-schizont arrest by inhibiting mitochondrial replication in Plasmodium falciparum. Antimicrob Agents Chemother 2014;58:4341-52.

28. Coronado LM, Nadovich CT, Spadafora C. Malarial hemozoin: from target to tool. Biochim Biophys Acta 2014;1840:2032-41. 